\title{
Ratings of Affective and Non-Affective Aspects of German Idioms in Second Language Processing
}

\begin{abstract}
In this paper psycholinguistic and emotional properties of 619 German idiomatic expressions are explored. The list of idiomatic expressions has been adapted from Citron et al. (2015), who have used it with German native speakers. In our study the same idioms were evaluated by Slovene learners of German as a foreign language. Our participants rated each idiom for emotional valence, emotional arousal, familiarity, concreteness, ambiguity (literality), semantic transparency, and figurativeness. They also had the task to describe the meaning of the German idioms and to rate their confidence about the attributed meaning. The aims of our study were (1) to provide descriptive norms for psycholinguistic and affective properties of a large set of idioms in German as a second language, (2) to explore the relationships between psycholinguistic and affective properties of idioms in German as a second language, and (3) to compare the ratings of the German native speakers studied in Citron et al. (2015) with the ratings of the Slovene second language learners from our study. On one hand, the results of the Slovene participants show many similarities with those of the German native speakers, on the other hand, they show a slight positivity bias and slightly shallower emotional processing of the German idioms. Our study provides data that could be useful for future studies investigating the role of affect in figurative language in a second language setting (methodology, translation science, language technology).
\end{abstract}

Keywords: idioms, affective properties, psycholinguistic properties, German, Slovene

\section{Language, Affect, and Idiom Processing}

Many studies addressing the relationship between emotion and language in human communication have shown that emotional aspects of words or 
word combinations affect comprehension processes in native language (Jacobs, 2011; Jacobs et al., 2015) and second language use (Conrad, Recio, \& Jacobs, 2011, p. 2). In everyday communication, emotional content is often conveyed with figurative (i.e., non-literal) expressions (Pollio et al., 1977). According to a number of studies (e.g., Fainsilber \& Ortony, 1987; Drew \& Holt, 1998), figurative expressions are preferred to literal language in several discourse types, presumably to elicit empathy in the addressee and thus to sound more convincing. Emotionally laden words exhibit higher levels of brain activation and are processed faster than neutral words, non-literal sentences evoke stronger emotional responses than literal sentences (Bohrn et al., 2012; Citron \& Goldberg, 2014). The question how these expressions contribute to the conveyance of affectivity still needs further investigation (Citron \& Goldberg, 2014). The meaning of a (part of a) sentence is considered figurative if the language user has to construct the intended meaning of a sentence not only by retrieving conventional word meanings from the mental lexicon and joining them according to the principle of semantic compositionality, but also by applying stored knowledge about their relationships to specific types of situations. In many languages different types of figurative expressions can be distinguished (e.g., metaphors, proverbs, idioms, and oxymora). Our study focussed on idioms, which in many languages belong to the most frequent type of figurative expressions. Idioms are strings of words whose phrasal meaning cannot be derived solely from the meaning of its constituent words and appears to be fully or partially arbitrary. Although the constituent words seem to contribute to the overall formal, semantic, and pragmatic properties of an idiom, most often the phrasal meaning of an idiom has to be learned to be fully understood or used in appropriate situations. Therefore it is often argued that it has to be stored in some way in a mental lexicon or knowledge system, together with its constraining formal properties and contextual preferences.

Several models have been proposed to account for L1 idiom processing, especially for idiom comprehension (for detailed overview, see Libben \& Titone, 2008; Cieślicka, 2015). According to lexical look-up models (Swinney \& Cutler, 1979, Bobrow \& Bell, 1973), idioms are fixed expressions listed in the mental lexicon. Linguistic processing of the string and retrieval of the idiomatic meaning proceed in parallel, with the retrieval of the idiomatic meaning being faster than the computation of its literal meaning. The idiom decomposition hypothesis (Gibbs, Nayak, \& Cutting, 1989) postulates that only decomposable idioms are processed faster than novel control phrases due to the contribution of their components to the figurative meaning of the idiomatic phrase. The graded salience hypothesis assumes that the more frequent, familiar, conventional or prototypical/stereotypical the information is, the more it is salient in one's mind (Giora, 2003, p. 28). Since salience always has processing priority, salient meanings (e.g., the figurative meaning of ambiguous familiar idioms) 
are predicted to be retrieved faster than their less salient meanings (e.g., the literal meaning of ambiguous familiar idioms). According to the configuration hypothesis (Cacciari \& Tabossi, 1988), idioms are processed word by word, until enough information has accumulated to render the sequence of words highly expected to be an idiom. At this point, the idiomatic meaning is retrieved. The superlemma model (Sprenger, Levelt, \& Kempen, 2006, pp. 174, 176) claims that idioms are both unitary and compositional, but at different levels of their cognitive representation. It assumes a separate representation of the idiom on the lexical-syntactic processing level, that is, the superlemma, which is a representation of the syntactic properties of the idiomatic phrase linked to its constituent lemmas. But these lemmas are not bound exclusively to an idiomatic meaning. Idiom processing is facilitated due to reduced competition between the constituent lemmas of the superlemma. Among the above described L1 models, the configuration hypothesis (Cacciari \& Tabossi, 1988) and the superlemma model (Sprenger et al., 2006) are most compatible with our view on processing German idioms (Petrič, 2014).

According to the L2 model of dual idiom representation (Abel, 2003), it is assumed that only non-decomposable and frequently occurring idioms are represented by entries on the conceptual level of the mental lexicon, whereas decomposable idioms are represented by lexical entries of their components. Storage in the mental lexicon, but also decomposability are assumed to facilitate idiom processing. In contrast to native speakers, L2 learners tend to assess the literal meaning of idioms more often (literality bias) since they do not develop as many idiom entries in their mental lexicon and have to rely more often on the literal analysis of idiom components. The literal salience model (Cieślicka, 2006; 2015) suggests that in L2 comprehension, literal meaning is generally more salient and therefore enjoys a processing advantage over the figurative meaning. The findings of Siyanova-Chanturia \& Conklin (2011) confirm that native speakers process idioms faster than novel phrases, but suggest that proficient non-native participants do not process idioms faster than novel phrases. These findings, that is, figurative meanings require more re-reading than literal ones, are in line with those in Cieślicka (2006). In contrast, the study of Conklin \& Schmitt (2008) does not observe any differences between figurative and literal meaning processing for either native or proficient non-native participants. The findings of Beck \& Weber (2016), as well as our own research on German idioms (Petrič, 2014), suggest that proficient non-native speakers process figurative meaning in a similar manner as native speakers and do not support the idiom diffusion model of Liontas (2002) that translatability of idioms from L1 to L2 has a significant impact. For proficient L2 users, Titone et al. (2015) come to the same conclusion as Beck \& Weber (2016). However, Matlock \& Heredia (2002) suggest that beginning L2 learners do not follow the same routes of idiom processing as native speakers since they seem to first access the literal 
meaning and translate it into to their native language. When becoming more proficient, L2 learners are able to bypass those first two less efficient steps in idiom processing. Our study follows the idea that differences in L1 and L2 idiom processing are not the result of a distinct manner of processing figurative expressions but rather the result of cross-linguistic differences (cf. Beck \& Weber, 2016).

\section{Description of the Experiment}

\section{Aims of the Study}

Several psycholinguistic properties (i.e., familiarity, meaningfulness, decomposability, semantic transparency, figurativeness, ambiguity, predictability and others) have been shown to affect idiom processing (for an overview, see Libben \& Titone, 2008). Our study is based on the work of Citron, Cacciari, Kucharski, Beck, Conrad, and Jacobs (2015), which not only included several psycholinguistic variables that have been already studied in some normative studies on idiomatic expressions in native language use (e.g., English, French), but also provided descriptive norms of affective variables (arousal, valence) and concreteness for German idioms.

The aims of our study were (1) to provide descriptive norms for psycholinguistic and affective properties of a large set of idioms in German as a second language, (2) to explore the relationships between psycholinguistic and affective properties of idioms in German as a second language, and (3) to compare the ratings of the German native speakers studied in Citron et al. (2015) with the scores of the Slovene second language learners from our study. Therefore a list of 619 German idioms, previously used with German native speakers (cf. Citron et al., 2015), was presented to Slovene learners of German as a foreign language as part of a research project on German idioms in foreign language learning (cf. Jesenšek, 2014). Our study provides data that could be used for future studies investigating the role of affect in figurative language in a second language setting.

\section{Participants}

A total number of 81 Slovene students of the German department of the University of Maribor participated in our study, but only the results of 73 (48 female and 25 male) could be included in our analysis. Our subjects were 19-22 
years old and had sufficient experience in working with standard computer programs (e.g., spreadsheets). Their native language was Slovene and after consulting lecturers from the same department, their proficiency in German as a foreign language was estimated reaching at least a B1 to B2 level ("independent level") according to the European Reference Frame for Language Competence (ERFLC).

\section{Language Material}

The language material in our study consisted of a list of 619 German idioms, previously selected by Citron et al. (2015) on the basis of several idiom lists and rated by German native speakers. Citron et al. (2015, pp. 7-8) used the following criteria of distinction between idioms and other types of figurative expressions:

- an idiom in the list should consist of a verbal phrase (VP) and one or several arguments, that is, to spill the beans or to give someone a hard time (but without distinguishing between internal and external syntactic valency of an idiom);

- the verb of an idiom should be capable of inflection (i.e., Person \& Tense);

- the meaning of an idiom should be conventionalised (contrary to metaphors) and

- an idiom should not consist of an entire sentence (contrary to proverbs like A man's home is his castle).

The idioms in the list were presented as infinitival clauses, as it was the case in the experiment with German native speakers conducted by Citron et al. (2015). The idiomatic expressions consisted of two to nine words or nine to 43 letters.

\section{Procedure}

Our participants received the same tasks, stimuli, and instructions as the German native speakers in the study of Citron et al. (2015, pp. 15-18). Employing a questionnaire in electronic spreadsheet form, we tried to obtain information on how our participants were rating the linguistic properties of the German idiomatic expressions on the list. After general instructions with information on the topic of the questionnaire, the participants received specific instructions on how to rate the idiomatic expressions according to several criteria and scales, three German examples and the list of 619 (unrated) German idioms. The participants of our study received the task to rate the following properties of the idiomatic expressions: familiarity, semantic 
transparency, figurativeness, concreteness, ambiguity, emotional valence, and emotional arousal. The participants also had the task to describe the meaning of the German idioms in their own words and subsequently to rate their confidence in the appropriateness of their description. The descriptions of the idioms written down by our participants (i.e., their knowledge of the idiomatic meaning) were assessed based on the descriptions in German idiom collections (Ephras, 2006; Udem, 2001) and rated dichotomously as "correct" [1] or "wrong" [0]. In the general instructions the participants were urged not to leave any expression unrated and to accomplish all tasks in a spontaneous fashion. In the specific instructions they were also asked to accomplish each rating task subsequently (column by column in the electronic spreadsheet): first emotional valence, then emotional arousal, followed by familiarity, semantic transparency, figurativeness, concreteness, and ambiguity, concluding with the description of the idiomatic meaning and the rating of their confidence in their own description).

\section{Variables in the Experiment}

In the experiment our participants rated or described the German idioms by the following variables: familiarity, semantic transparency, figurativeness, concreteness, ambiguity (also known as literality or literal plausibility), emotional valence, emotional arousal, confidence into one's own idiomatic knowledge and knowledge of idiomatic meaning. Ambiguity was also determined by the experimenters of the study Citron et al. (2015). Another variable, that is, the length of the idiomatic construction, was calculated by Citron et al. (2015). In the instructions the participants were given descriptions of the rating scales and typical examples (for a detailed view of all instructions, scales and examples, cf. Citron et al., 2015, Appendix A).

Familiarity refers to the subjective frequency of exposure to idioms (Titone \& Connine, 1994), that is, how often one has read or heard an idiom. Familiarity may differ from objective frequency estimates of expressions occurring in written and spoken texts. The Slovene students had to rate the familiarity of the German idioms (Familiarity.M) according to the same seven-point Likert-scale (ranging from one to seven, that is, from very unfamiliar to very familiar) as the German native speakers in Citron et al. (2015).

Semantic transparency (Sem.transp.M) relates to the degree of how easy the idiomatic meaning of a German idiom could be derived from the (literal) meanings of its constituents. The German native speakers in Citron et al. (2015) and our Slovene participants were instructed to rate the semantic transparency of the German idioms according to a seven-point Likert-scale (ranging from one to seven, i.e., from very opaque to very transparent). 
Figurativeness relates to the degree to which an idiomatic expression is perceived as expressing a non-literal meaning. The figurativeness of the German idioms (Figurative.M) was rated by the German native speakers in Citron et al. (2015) and our Slovene participants according to a seven-point Likert-scale (ranging from one to seven, i.e., from non-figurative to very figurative).

Concreteness (Concrete. $M$ ) was described as a property of a linguistic element to be experienced with one or more of the human senses. The German native speakers in Citron et al. (2015) and the Slovene second language learners in our study were instructed to rate the concreteness of the German idioms according to a seven-point Likert scale (ranging from one to seven, i.e., from very abstract to very concrete).

Ambiguity (also called literality or literal plausibility) refers to whether an idiom also has a semantically plausible literal meaning (Cronk, Lima, \& Schweigert, 1993) if occurring in an appropriate context. In Citron et al. (2015) the German idioms were determined by the experimenters as ambiguous or not ambiguous (variable Ambiguity.D), but in our study the Slovene participants were instructed to determine idiom ambiguity themselves (variable Ambiguity).

Emotional valence (Emo.val.M) was one of the two obtained affective variables describing to which extent a stimulus was rated positive or negative (cf. Russell, 1980). The German native speakers in Citron et al. (2015) and the Slovene second language learners in our study were instructed to rate the German idioms according to a seven-point scale ranging from -3 to +3 (i.e., from very negative to very positive).

Another affective variable was included during our statistical analysis by calculating the square of emotional valence, which was called emotional valence $^{2}$ (Emo.val.M^2 or Emo.val.Msq). This variable represents the degree of stimulus emotionality independent of its polarity and enables us to explore potential quadratic relationships between emotional valence and other variables.

Emotional arousal (Arousal.M) was the second affective variable employed in both studies and referred to the extent an event was emotionally stimulating, regardless of its polarity (Barrett \& Russell, 1998). The German native speakers in Citron et al. (2015) and the Slovene participants from our study were instructed to rate the emotional arousal of a German idiom according to a seven-point Likert scale (ranging from one to seven, i.e., from not emotionally stimulating to very stimulating or intense).

Knowledge of idiomatic meaning refers to whether or not the correct idiomatic meaning is known. Some studies (Tabossi, Arduino, \& Fanari, 2011) tested this variable by asking participants to provide a written explanation of the idiomatic meaning, whereas others measured the extent to which participants were confident about their own knowledge of the idiomatic meaning (Bonin, Méot, \& Bugaiska, 2013; Libben \& Titone, 2008; 
Titone \& Connine, 1994). Since knowledge of the idiomatic meaning and confidence can differ, we tested these two variables separately. The German participants in Citron et al. (2015) and our Slovene participants received the task to describe the meaning of the German idioms in their own words, that is, their knowledge of the idiomatic meaning (variable Knowidiom. meaning, measured in \%). The descriptions were evaluated as "correct" or "false" by comparing them with those provided in collections of German idioms (Ephras, 2006; Udem, 2001). Due to evaluation issues concerning the Slovene participant data, this variable has not been included in the statistical analysis presented in this article.

Confidence (Confidence.M) refers to the extent to which participants are sure about their own knowledge (Bonin et al., 2013). The German native speakers in the study of Citron et al. (2015) and the Slovene participants in our study were instructed to rate their own definitions of the idiom meanings according to a seven-point Likert scale (ranging from one to seven, i.e., from poor to excellent knowledge). In contrast to the German participants, the Slovene second language learners were instructed to rate their idiomatic knowledge after they had already provided the definitions of the idioms meanings.

The length of an idiom, that is, the number of words [Length.W] or letters [Length.L] it consists of, was determined by the experimenters of the study Citron et al. (2015) and was included in the analysis as a psycholinguistic variable since online-studies have shown that it has substantial impact on the cognitive processing of phrases.

\section{Expected Relationships between the Variables}

The sensitivity to emotional content in a second language is still an open issue in research. According to some researchers (Bond \& Lai, 1986), second language processing would differ from first language processing by increased emotional distance (shallow encoding of emotional content, emotion words experienced in fewer contexts). Recent research rather seems to support the assumption that second language processing is not always less emotional but rather modulated by several factors such as age of acquisition, proficiency level and exposure to the second language environment (Conrad et al., 2011, p. 2). Since the proficiency of the second language learners included in our study has reached a sufficiently high level (i.e., B1 or B2 according to ERFLC), we assumed that the cognitive processing of German idiomatic expressions in our second language learners was qualitatively comparable to the processing in German native speakers. Therefore, we generally expected to replicate correlations between psycholinguistic and affective variables found in the study of Citron et al. (2015) with German native speakers. 
According to our general assumption from the previous paragraph, we expected to obtain positive correlations between familiarity, knowledge, and confidence that have been found in previous normative studies on idioms in native language use (Citron et al., 2015; Bonin et al., 2013; Libben \& Titone, 2008; Tabossi et al., 2011).

Since we assumed a basic preference for less cognitive complexity, we also expected positive correlations between familiarity on the one hand, and transparency and concreteness on the other, as well as a negative correlation between familiarity and idiom length: that is, it should be easier for a second language learner to become familiar with shorter, transparent and/or more concrete idioms than with longer, opaque and/or more abstract ones. Furthermore, we expected a negative relationship between familiarity and figurativeness, since constituents in figurative expressions exhibit less semantic overlap than those in literal expressions (cf. Beeman, 1998) and should be more difficult to decode.

Furthermore, we expected positive correlations between familiarity on one hand and both affective variables (valence and arousal) on the other hand, that is, it should be easier for a second language learner to become familiar with expressions of polarizing and stimulating content (high contrast between semantic levels) than with expressions of neutral content (low contrast between semantic levels).

Concreteness, semantic transparency, figurativeness, idiom length, valence, and arousal have not yet been tested for idioms in second language acquisition. Therefore we expected similar correlations as found and discussed in Citron et al. (2015) for German native speakers: positive correlations between transparency and concreteness, transparency and length, figurativeness and length, transparency and arousal, concreteness and arousal, figurativeness and arousal, and negative correlations between transparency and figurativeness and between concreteness and figurativeness. Furthermore, we expected positive correlations between knowledge and confidence on the one hand, and transparency and concreteness on the other in our second language data.

We also tested whether the properties of ambiguous and unambiguous idioms differed, and how they were correlated with the other studied variables. In line with the findings in Citron et al. (2015, pp. 12-13), we expected negative correlations between ambiguity on the one hand, and valence and arousal on the other. Furthermore, in Citron et al. (2015) ambiguous idioms were rated more concrete than unambiguous ones, possibly because it was easier to establish a link to the literal meaning of an ambiguous idiom than to imagine the meaning of unambiguous idioms, exhibiting figurative meaning only. Another difference found in Citron et al. (2015) was that unambiguous idioms were better known than ambiguous ones. Similar relationships were also expected in our second language data. Furthermore, we also expected a negative correlation between 
ambiguity and transparency, that is, ambiguous idioms should be rated as less transparent, and a positive correlation between ambiguity and figurativeness, that is, ambiguous idioms should be rated as more figurative.

Concerning the relationships between affective variables, we expected to replicate the results based on German idioms in native language use (Citron et al., 2015) and single words (e.g., Citron et al., 2014) - namely, a quadratic relationship between valence and arousal (i.e., the more valenced an idiom, the more arousing it is) and a negative linear relationship (i.e., negative idioms are rated as more arousing than positive idioms).

\section{Results of the Experiment}

\section{Descriptive Statistics and Distribution of Variables}

Table 1 displays descriptive statistic values for the variables obtained in this experiment: the number of observations for every variable $(n)$, the average value (mean) and its standard deviation $(s d)$, the central value (median) and its median absolute deviation ( $\mathrm{mad}$ ), its standard error ( $\mathrm{Se}$ ) and also information on the distributional characteristics of a variable, that is, its skewness (skew) and peakedness or tail extremity (kurtosis). Knowledge of the idiomatic meaning is not included in this table. The distribution of the variables was checked visually and numerically with specific tests in the statistics program $R$ and found to be acceptable to the assumptions made for applying regression techniques (Pena \& Slate, 2014; Ruginski, 2016; Prabhakaran, 2017); only the variable length of idiom was logarithmically transformed.

Table 1

Descriptive statistics of the obtained variables

\begin{tabular}{|l|r|r|c|r|c|r|c|c|}
\hline \multicolumn{1}{|c|}{ Variable } & $\mathrm{n}$ & \multicolumn{1}{c|}{ mean } & \multicolumn{1}{c|}{ sd } & median & mad & skew & kurtosis & Se \\
\hline Emotional valence & 45645 & -0.19 & 1.94 & 0 & 2.97 & 0.19 & -1.16 & 0.01 \\
\hline Emotional arousal & 45690 & 4.00 & 1.73 & 4 & 1.48 & -0.06 & -0.83 & 0.01 \\
\hline Familiarity & 45730 & 4.40 & 1.82 & 5 & 1.48 & -0.24 & -0.97 & 0.01 \\
\hline Semantic transparency & 45229 & 3.91 & 1.78 & 4 & 1.48 & 0.07 & -1.04 & 0.01 \\
\hline Figurativeness & 45727 & 4.72 & 1.63 & 5 & 1.48 & -0.44 & -0.55 & 0.01 \\
\hline Concreteness & 45721 & 3.71 & 1.68 & 4 & 1.48 & 0.07 & -0.82 & 0.01 \\
\hline Ambiguity & 45103 & 0.36 & 0.48 & 0 & 0 & 0.56 & -1.68 & 0 \\
\hline Confidence & 42447 & 5.08 & 1.58 & 5 & 1.48 & -0.59 & -0.33 & 0.01 \\
\hline Length.L & 45806 & 22.89 & 5.79 & 22 & 5.93 & 0.69 & 0.46 & 0.03 \\
\hline Length.W & 45806 & 4.48 & 1.29 & 4 & 1.48 & 0.40 & -0.12 & 0.01 \\
\hline
\end{tabular}


The mean values of the ratings of both participant groups, that is, the German native speakers (L1-German) studied in Citron et al. (2015) and the Slovene second language learners (L2-German) from our study, were statistically compared with a MANOVA (i.e., with participant groups and idioms as independent variables and all affective and psycholinguistic variables together as dependent variable). According to MANOVA the difference between the groups was significant $($ Pillai $=0.7985 ; \mathrm{F}(8,611)=302.58 ; \mathrm{p}<0.001)$. Table 2 shows that the differences between the mean values of nearly all variables of both participant groups were significant $(\mathrm{p}<0.05)$, except in the case of figurativeness with no significant mean value difference between the participant groups ( 4.72 vs. $4.70 ; \mathrm{p}=0.22)$.

Table 2

Mean values of Slovene and German participants and F-tests in MANOVA

\begin{tabular}{|l|r|r|r|r|r|}
\hline \multicolumn{1}{|c|}{ Variable } & $\begin{array}{c}\text { L2- } \\
\text { German }\end{array}$ & $\begin{array}{c}\text { L1- } \\
\text { German }\end{array}$ & F-value & df & p-value \\
\hline Valence & -0.19 & -0.58 & $\mathbf{3 8 9 . 4 1}$ & 1,618 & $<0.001$ \\
\hline Arousal & 4.00 & 3.82 & $\mathbf{9 0 . 1 4}$ & 1,618 & $<0.001$ \\
\hline Familiarity & 4.39 & 4.76 & $\mathbf{1 9 2 . 6 0}$ & 1,618 & $<0.001$ \\
\hline Transparency & 3.91 & 4.13 & $\mathbf{4 5 . 9 4}$ & 1,618 & $<0.001$ \\
\hline Figurativeness & 4.72 & 4.70 & 1.51 & 1,618 & 0.22 \\
\hline Concreteness & 3.71 & 3.34 & $\mathbf{1 7 2 . 5 8}$ & 1,618 & $<0.001$ \\
\hline Ambiguity & 0.36 & 0.47 & $\mathbf{4 7 . 8 5}$ & 1,618 & $<0.001$ \\
\hline Confidence & 5.06 & 6.10 & $\mathbf{1 5 5 2 . 3 7}$ & 1,618 & $<0.001$ \\
\hline
\end{tabular}

The mean values of nearly all scales were significantly different in the data of both participant groups, however, the correlation values show striking similarities, that is, strong correlations in the case of emotional valence $(93 \%)$, emotional arousal $(78 \%)$, familiarity (54\%), semantic transparency (54\%), figurativeness $(60 \%)$, concreteness $(51 \%)$, and ambiguity $(67 \%)$. In the case of confidence the German and Slovene participants differed strongly, thus the correlation coefficient was very low and not significant $(-3 \%)$. From our point of view, these results suggest that L1 and L2 processing of idioms by and large follow the same principles. However, MANOVA displayed quantitative differences between the participant groups, estimated to belong to different ERFLC competence levels (B1/B2 vs. C2), and most of the test results suggest deeper idiomatic knowledge of the German native speakers. 


\section{Internal and External Validity}

An internal consistency analysis shows the reliability of an implemented measure in a study. The most often used measure of the internal consistency of evaluation scales is Cronbach's alpha: the higher the $\alpha$ coefficient, the more the items have shared covariance and probably measure the same underlying evaluation scale or concept. According to our consistency analysis (cf. Revelle, 2018 on R-package psych), the evaluation data of all the scales in our experiment can be considered consistent since Cronbach's alpha reach values above the threshold $(\alpha>0.7)$, which according to Kline (1999) indicates high consistency or reliability of the evaluation data.

Table 3

Internal consistency of scales (Cronbach's alpha values)

\begin{tabular}{|c|c|c|c|c|c|c|c|}
\hline Arousal & Valence & Familiarity & Transparency & Figurativeness & Concreteness & Ambiguity & Confidence \\
\hline 0.91 & 0.98 & 0.94 & 0.9 & 0.89 & 0.82 & 0.95 & 0.88 \\
\hline
\end{tabular}

Inter-rater reliability indicates to which extent the ratings of different participants agree with one another. We used Krippendorff's method to analyse the inter-rater reliability of our rating data. Krippendorff's alpha calculates the probability of empirical agreements and deviations (Nordmann, Cleland, \& Bull, 2014, p. 5). Our analysis with 73 raters and 619 items indicates that the ratings of the Slovene participants reached only a low level of agreement, much below Krippendorff's recommended threshold of 0.67 and therefore the ratings can be assumed to be not independent from the participants in the study. The highest agreement was found with emotional valence, followed by ambiguity and familiarity, the lowest with confidence and concreteness. These values indicate that the ratings of the idiom properties are only to a small degree independent of our participants and therefore they exhibit a low degree of replicability or external validity. Similar low values of inter-rater agreement (based on Krippendorff's alpha) have been found by Nordmann \& Jambazova (2017, p. 202) in a rating study on English and Bulgarian idioms. According to Nordmann et al. (2014) the relationship between the evaluations can be consistent (i.e., the evaluation scale can be internal consistent), but this does not indicate that different participants show high agreement (i.e., high inter-rater reliability). 
Table 4

Inter-rater reliability (Krippendorff's alpha values, calculated with $R$ package irr, cf. Gamer, Lemon \& Fellows, 2012)

\begin{tabular}{|l|c|c|c|c|c|c|c|c|}
\hline \multicolumn{2}{|c|}{ Arousal } & Valence & Familiarity & $\begin{array}{c}\text { Trans- } \\
\text { parency }\end{array}$ & $\begin{array}{c}\text { Figura- } \\
\text { tiveness }\end{array}$ & $\begin{array}{c}\text { Concret- } \\
\text { eness }\end{array}$ & Ambiguity & Confidence \\
\hline items & 619 & 619 & 619 & 619 & 619 & 619 & 619 & 619 \\
\hline raters & 73 & 73 & 73 & 73 & 73 & 73 & 73 & 73 \\
\hline value & 0.0798 & 0.3177 & 0.1454 & 0.0631 & 0.0567 & 0.0325 & 0.1703 & 0.0278 \\
\hline
\end{tabular}

\section{Relationships among Variables}

Statistical procedures and criteria. In order to study the relationships among affective and non-affective variables, we mainly followed the statistical procedure described in Citron et al. (2015, p. 10). We calculated partial correlations between each variable. Significant partial correlations (with $\mathrm{p}<0.05$ ) were distinguished according to their correlation coefficient $r$ as small correlations $(0<r< \pm 0.1)$, moderate correlations $( \pm 0.1<r< \pm 0.3)$ and large correlations $( \pm 0.3<r)$. In contrast to Citron et al. $(2015$, p. 9), who applied a distribution independent bootstrapping technique for all parametric statistical analyses, we used ordinary least squares regression and mixed effects regression modelling techniques. Since it was known from the literature (Efron \& Tibshirani, 1993) that emotional valence and arousal ratings show a quadratic relationship (Figure 1), we also included squared emotional valence as predictor for arousal ratings. Suitable regression models were chosen on the basis of backward selection.

Correlations between affective variables. In the presented idiom list adapted from Citron et al. (2015), idioms with negative valence $(n=422)$ prevailed over such with positive valence $(n=194)$ or zero valence $(n=3)$. The Slovene participants rated 372 idioms as negative, 245 as positive and 2 as zero valenced. The data of the Slovene participants indicate a slight positivity bias compared to the ratings of the German participants. This is most apparent with average valence ratings between -0.5 and 0.5 , which show a balanced ratio between negative and positive ratings in the Slovene participant data ( 80 vs. 76) and a stronger negative tendency in the German participant data (131 vs. 34). However, the above described overall ratio in the valence ratings of the German and Slovene participants is mirrored in the evaluation data of both participant groups: linear emotional valence was negatively correlated with emotional arousal (i.e., in the data of the Slovene participants, Pearson's correlation coefficient $r=-0.254$, Spearman's rank correlation coefficient $r o=$ $-0.339, \mathrm{p}<0.05$, calculated with the R package ppcor, cf. Kim, 2015). According 
to Cacciari (1998) and Drew and Holt (1988), this result seems to be typical for idioms as an indirect form of communication, preferred to the more straight forward literal expressions in the case of statements with negative connotation. The non-linear (U-shaped) relationship between valence and arousal found in the data of the Slovene and German participants also corresponds to the U-shaped relationship between emotional dimensions found with single words (cf. Bradley \& Lang, 1999; Citron et al., 2015, p. 11). The non-linear relationship is less pronounced in the data of the Slovene participants compared to the German participants. The following Figure 1 reports the partial correlations between emotional arousal and emotional valence in the data of both participant groups. Due to some differences in statistical methodology, the numbers for the German participants in the following table slightly differ from those in Citron et al. (2015).

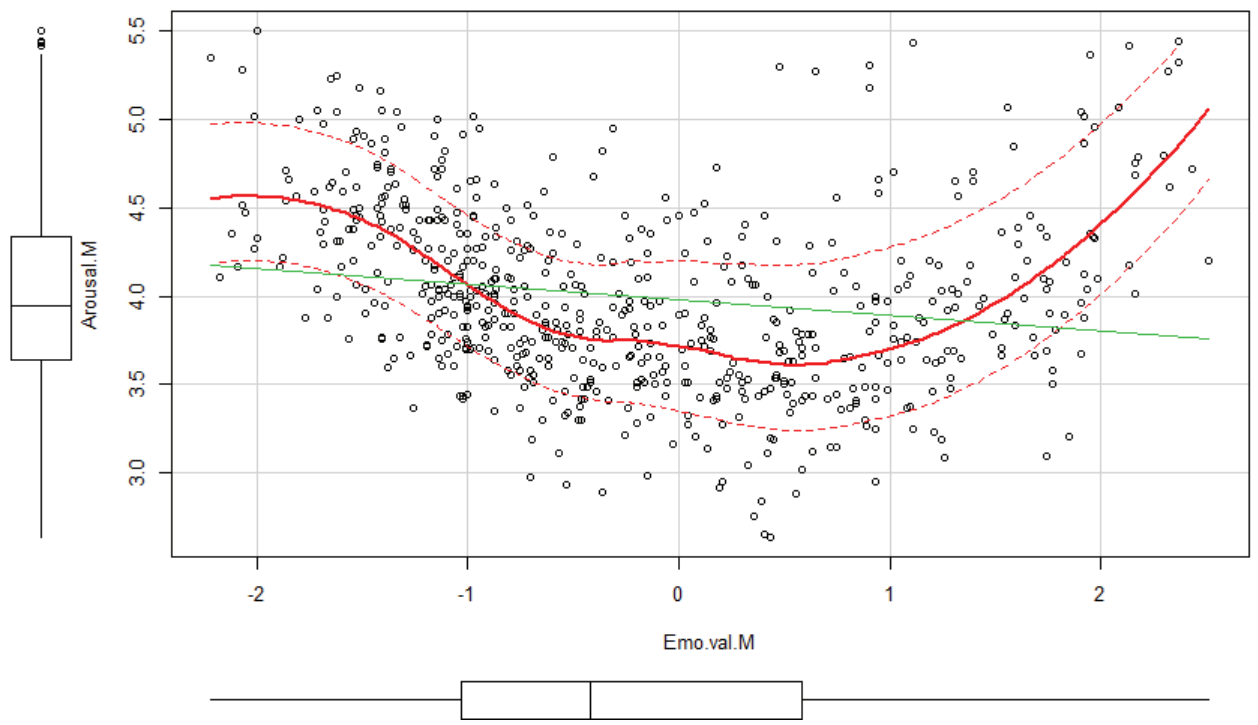

Figure 1. Distribution of the affective variables in the ratings of the Slovene learners of German as a foreign language (green $=$ regression line, red $=$ trend line).

Correlations between affective and psycholinguistic variables. The partial correlations between each affective variable and non-affective variables in our experiment with Slovene second language learners are summarized in Table 5, showing Pearson's partial correlation coefficients (calculated by $\mathrm{R}$ package $R c m d r$, cf. Fox, 2017). Significant correlations with $\mathrm{p}<0.05$ are printed bold, marginally significant correlations with $0.05<\mathrm{p}<0.10$ are in italics. Due to minor differences in statistic methodology, the numbers for the German participants slightly differ from those given in Citron et al. (2015). 
Table 5

Partial correlation coefficients between affective and non-affective variables in the data of the Slovene and German participants

\begin{tabular}{|l|c|c|c|c|}
\hline \multirow{2}{*}{ Variable } & \multicolumn{2}{|c|}{ Emotional Arousal } & \multicolumn{2}{c|}{ Emotional Valence } \\
\cline { 2 - 5 } & Slovene & German & Slovene & German \\
\hline Familiarity & $\mathbf{0 , 2 4}$ & $\mathbf{0 , 1 5}$ & $\mathbf{0 , 0 9}$ & $\mathbf{0 , 1 6}$ \\
\hline Transparency & $\mathbf{0 , 1 9}$ & $\mathbf{0 , 2 5}$ & 0,04 & 0,07 \\
\hline Figurativeness & $\mathbf{0 , 2 7}$ & $\mathbf{0 , 3 1}$ & $\mathbf{0 , 1 1}$ & $-0,01$ \\
\hline Concreteness & $-0,02$ & $\mathbf{0 , 0 8}$ & 0,03 & $-0,08$ \\
\hline Confidence & 0,01 & $-0,07$ & 0,01 & 0,00 \\
\hline Length.letters & 0,05 & 0,01 & 0,00 & $-0,03$ \\
\hline Length.words & $-0,03$ & $-0,01$ & 0,03 & $\mathbf{0 , 0 9}$ \\
\hline
\end{tabular}

The participants from both groups associated more familiar, transparent, and figurative German idioms with higher levels of emotional arousal. These three partial correlations were moderately high, with figurativeness showing stronger correlation than familiarity and semantic transparency. The correlation between familiarity and arousal in the Slovene ratings was stronger than in the German ratings. In case of transparency we observed the opposite. In contrast to the German participant data, the correlation between arousal and concreteness was not significant in the data of the Slovene participants.

Both participant groups associated more familiar German idioms with higher levels of linear emotional valence, though more strongly in the German data. The groups differed in other cases: figurativeness was moderately correlated in the Slovene data, idiom length, measured as number of words, in the German data.

Correlations among psycholinguistic variables. The partial correlations between each pair of non-affective variables in our experiment with Slovene second language learners (SI) and German native speakers (D) are summarized in Table 6, showing parametric Pearson partial correlation coefficients (calculated by R package Rcmdr, cf. Fox, 2017). Significant correlations with $\mathrm{p}<0.05$ are printed bold, marginally significant correlations with $0.05<\mathrm{p}<0.10$ are in italics.

We found twelve significant partial correlations between pairs of nonaffective variables in the data of the Slovene participants. Four of these twelve correlations were large and eight of them moderate, nine of twelve correlations were positive, three were negative. The obtained significant partial correlations are in concord with our previously described expectations, except one (i.e., between familiarity and figurativeness). 


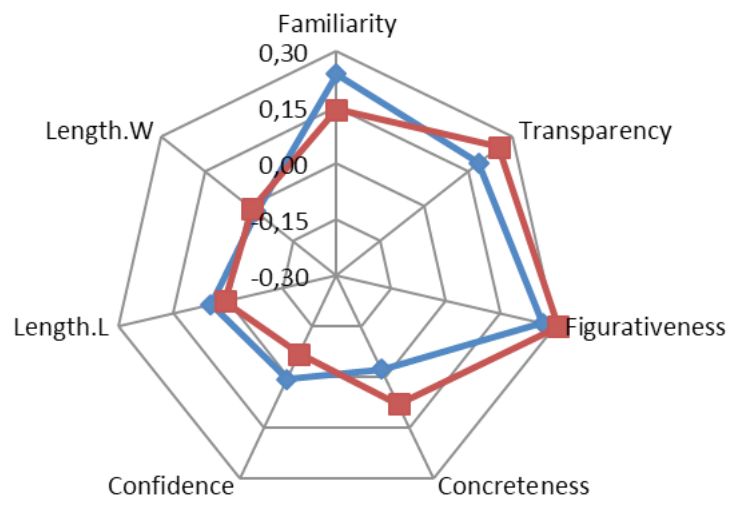

$\_$Emotional Arousal Slovene

- Emotional Arousal German

Figure 2. Partial correlations between emotional arousal and non-affective variables (ratings of German and Slovene participants).

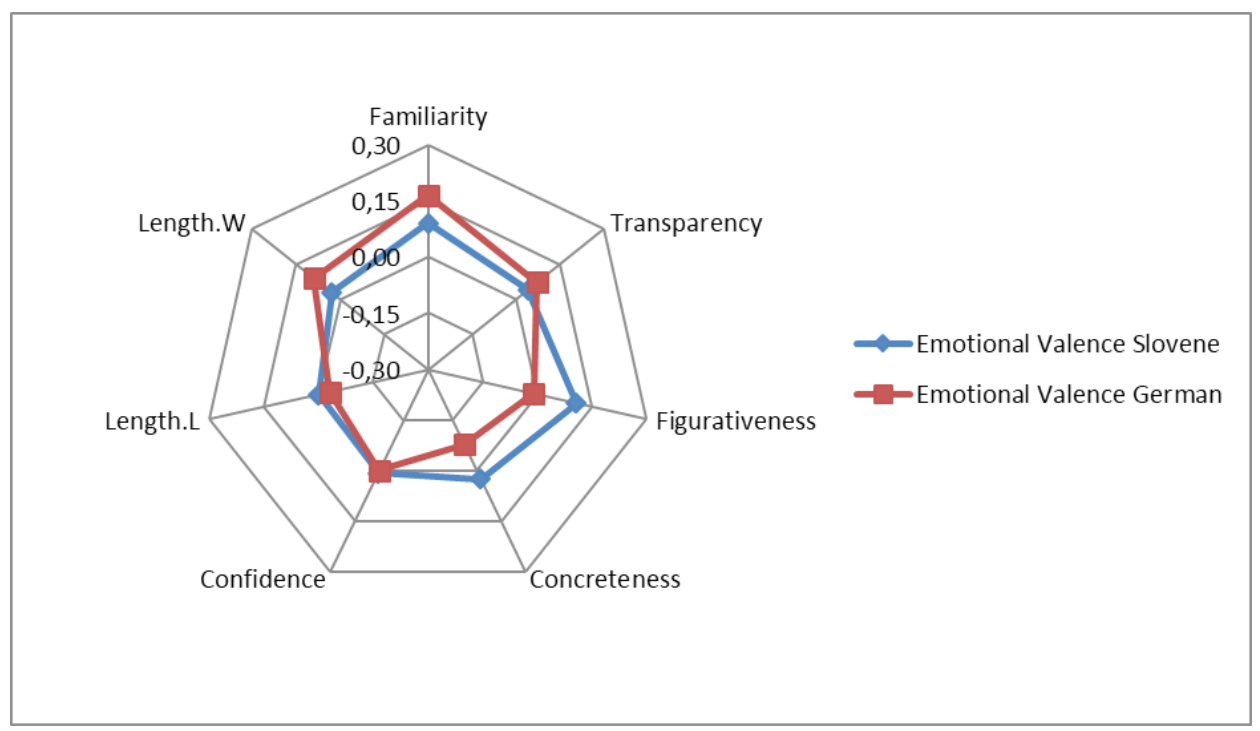

Figure 3. Partial correlations between emotional valence and non-affective variables (ratings of German and Slovene participants). 


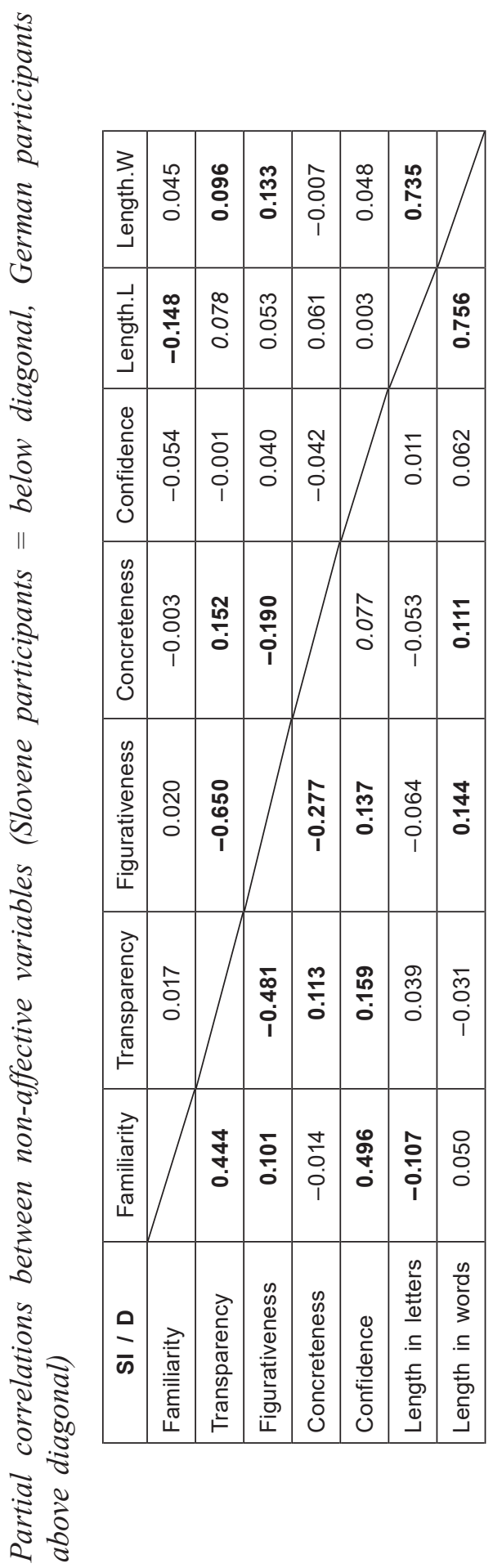


The four large correlations obtained from the data were the positive correlations between familiarity and transparency, familiarity and confidence, and between both measures of idiom length (i.e., number of letters vs. words), and the negative correlation between transparency and figurativeness. The large positive correlation between familiarity and transparency of German idioms corresponds to experimental results obtained with single words (Montefinese, Ambrosini, Fairfield, \& Mammarella, 2014). The large positive correlation between familiarity and confidence was expected from other idiom studies (Citron et al., 2015; Bonin et al., 2013; Libben \& Titone, 2008; Tabossi et al., 2011). The large negative correlation between transparency and figurativeness was expected and also observed with German native speakers in the study of Citron et al. (2015, p. 12): a figurative meaning is semantically less transparent and vice versa.

The eight moderate correlations from the Slovene data were either positive correlations (i.e., between familiarity and figurativeness, transparency and concreteness, transparency and confidence, figurativeness and confidence, figurativeness and idiom length, and between concreteness and idiom length), or negative correlations (i.e., between familiarity and idiom length, and between figurativeness and concreteness). These moderate correlations (with the exception of the first mentioned) were expected due to similar, though not always significant relationships in the study of Citron et al. (2015).

From the ratings of the German participants (cf. Citron et al., 2015) eight significant partial correlations between non-affective variables were obtained: one large positive correlation (between both measures of idiom length), one large negative correlation (between transparency and figurativeness), three positive moderate correlations (between transparency and concreteness, transparency and idiom length, and between figurativeness and idiom length), and two negative moderate correlations (between familiarity and idiom length, and between figurativeness and concreteness). Confidence was not in a significant relationship with any of the other psycholinguistic variables, but knowledge of idiomatic meaning (excluded from analysis of the Slovene participant data) was highly correlated with familiarity.

In both participant groups (German and Slovene), the following significant correlations could be observed: between familiarity and idiomatic knowledge (i.e., confidence ratings of the Slovene participants vs. percentage of correct idiomatic descriptions of the German participants), familiarity and idiom length (i.e., shorter idioms were more familiar), transparency and figurativeness (i.e., the more transparent an idiom, the less figurative it was rated, and vice versa), transparency and concreteness (i.e., more transparent idioms were also rated as more concrete), figurativeness and concreteness (i.e., the more figurative an idiom was rated, the more it was rated as abstract), and between figurativeness and idiom length (i.e., idioms with a larger number of constituent words 
were rated as more figurative). Unsurprisingly, the high correlation between both measures of idiom length was found in the data of both participant groups.

Smaller differences between both participant groups concern the moderate correlations with idiom length. The Slovene participants associated longer idioms with higher levels of figurativeness and concreteness, but the German participants with higher levels of figurativeness and transparency. Both scales (transparency and concreteness) are positively correlated with each other and similar with respect to their hearer-friendly effect. Two more obvious differences between the participant groups concern the positive correlations between familiarity on the one hand, and transparency and figurativeness on the other, the former showing a strong correlation, the latter a moderate one. The strong correlation between familiarity and transparency was expected since it should be easier for the Slovene second language learners to become familiar with transparent idioms. The (unexpected) positive partial correlation between familiarity and figurativeness seems to be due to the moderating effect of transparency in the Slovene participant data. The simple (bivariate) correlation between familiarity and figurativeness was negative $(r=-0.18, \mathrm{p}<0.05)$ and seemed to confirm our assumption that figurative expressions are of greater cognitive complexity than transparent expressions and therefore more difficult to learn and become familiar with.

Ambiguous compared to unambiguous idioms. In contrast to the procedure in Citron et al. (2015) where idiom ambiguity was categorized by the researchers, the task to rate the ambiguity of the presented German idioms was accomplished by the Slovene second language learners of our study. The ratings of the Slovene participants and the German researchers of the study Citron et al. (2015) were strongly correlated $(r=0,665 ; n=619)$, but nonetheless, the difference between the L1- and L2-evaluations of idiom ambiguity was significant according to a non-parametric Kruskal-Wallis-test $(\chi 2=275.03$; $\mathrm{df}=1 ; \mathrm{p}<$ $0.001)$. The Slovene participants assigned only about $36.4 \%$ to the group of ambiguous idioms, the German researchers of the study Citron et al. (2015) about $47.3 \%$. It is unclear whether the Slovene participants spontaneously recognized only the figurative meaning or rather only the literal meaning of the presented ambiguous German idioms. According to Abel (2003), second language learners rely to a greater extent on the literal meaning of idiom components than native speakers. But since the participants knew the task was about German idioms, it is also very likely that the Slovene participants were biased and that plausible literal meanings came less often to their minds.

In order to compare the effect of idiom ambiguity on the ratings of the Slovene and German participants, we used the dichotomous categorization of the experimenters in Citron et al. (2015). The mean values of the Slovene and German participants according to ambiguous and unambiguous idioms are 
provided in Table 7 (due to our methodology the values for the German participants in some cases slightly differ from those given in Citron et al. (2015, pp. 12-13, 14). Significant differences between mean values in each participant group were subject to MANOVA (i.e., with all affective and non-affective variables as dependent variables and ambiguity determined by Citron et al. (2015) as independent variable) and are printed bold (i.e., with $\mathrm{p}<0.05$ as significance threshold for individual variables). The overall MANOVA results for the Slovene participants (Pillai $=0.1336 ; \mathrm{F}(10,608)=9.38 ; \mathrm{p}<0.001)$ and the German participants (Pillai $=0.2089 ; \mathrm{F}(11,607)=14.57 ; \mathrm{p}<0.001)$ were significant.

Table 7

Mean values of variables accounting for Ambiguity (as determined by Citron et al., 2015)

\begin{tabular}{|l|rr|rr|}
\hline \multicolumn{1}{|c|}{ Variable } & \multicolumn{2}{c|}{ Slovene participants } & \multicolumn{2}{c|}{ German participants } \\
& Ambiguous & Unambiguous & Ambiguous & Unambiguous \\
\hline Emotional valence & -0.21 & -0.17 & -0.62 & -0.56 \\
Emotional valence ${ }^{2}$ & 1.03 & 1.34 & 1.86 & 2.29 \\
Emotional arousal & 3.92 & 4.07 & 3.70 & 3.92 \\
Familiarity & 4.39 & 4.40 & 4.75 & 4.78 \\
Semantic transparency & 3.88 & 3.93 & 4.06 & 4.19 \\
Figurativeness & 4.64 & 4.79 & 4.66 & 4.73 \\
Concreteness & 3.80 & 3.62 & 3.63 & 3.08 \\
Confidence & 5.06 & 5.07 & 6.11 & 6.09 \\
Idiomatic Knowledge & $\ldots$ & $\ldots$ & 89.61 & 91.91 \\
Length in letters & 23 & 23 & 23 & 23 \\
Length in words & 5 & 4 & 5 & 4 \\
\hline Number of idioms & 293 & 326 & 293 & 326 \\
\hline
\end{tabular}

Both participant groups rated ambiguous German idioms as less valenced (i.e., valence squared, independently of whether positively or negatively) and less stimulating, but as more concrete than the unambiguous idioms. Citron et al. (2015, p. 13) argue that the literal plausible meaning of ambiguous idioms interferes with its idiomatic meaning and reduces emotional rating values, but makes it easier to produce mental images which can be more directly associated with sensory modalities. Furthermore, the Slovene participants rated ambiguous idioms as less figurative. The German participants showed the same (but not significant) tendency. The tendency to rate ambiguous idioms as less figurative than unambiguous idioms seems to fit with data from neuro-imaging showing the stronger emotional engagement of figurative formulations over their 
literal counterparts (Citron \& Goldberg, 2014). The idiomatic knowledge of the German participants (i.e., the percentage of correct idiomatic descriptions) reached higher levels with unambiguous idioms than with ambiguous idioms. This outcome is in line with the suggestion that the plausible literal interpretation of ambiguous idioms causes interference with the figurative interpretation and makes it more difficult to describe the meaning. This relationship has not been statistically tested yet with the Slovene data. Mean confidence levels (i.e., another way to obtain information on idiom knowledge) were not significantly different for ambiguous and unambiguous idioms in neither of the two participant groups.

\section{Regression models}

Regression models with familiarity as dependent variable. The ordinary least squares regression model S1 for the estimation of idiom familiarity (Familiarity.M), including six significant predictors, can account for 59\% of the variance in the data of the Slovene participants $\left(\mathrm{R}^{2}=0.58 ; \mathrm{r}=0.77\right.$; $\mathrm{F}(6,612)=145.3 ; \mathrm{p}<0.001)$ :

(S1) Estimated familiarity $=-2.61+0.29 *$ emotional arousal $+0.05 *$ emotional valence $+0.49 *$ semantic transparency $+0.88 *$ confidence $0.19 * \log ($ Length.L $)+0.28 *$ ambiguity.

According to Model S1, familiarity reached higher levels if the idiom was rated more stimulating, more positive, more transparent, shorter and more ambiguous (i.e., literally plausible). The model of the Slovene evaluation data resembles the model of the German participant data (G1) in several aspects. The regression line was as follows (cf. Citron et al. (2015, p. 12):

(G1) Estimated familiarity $=0.19 *$ arousal $(\log 10)+0.38 *$ knowledge $0.23 *$ length in letters $(\log 10)+0.11 *$ emotional valence $-0.14 *$ emotional valence $^{2}$

In the German participant data, knowledge of idiomatic meaning was the strongest predictor for idiom familiarity. This result corresponded to the strong effect of confidence in the regression analysis of the Slovene participant data. Furthermore, we could observe that higher levels of familiarity were in both participant groups attributed to shorter German idioms and to those rated more 
stimulating and positive. The relationship between familiarity and valence complies with the experimental results on emotional-laden words (cf. Citron et al., 2015, p. 12), which could imply that participants in normative studies prefer to declare familiarity with positive concepts and less so with negative ones. The differences between the German and Slovene familiarity estimates concern valence squared, semantic transparency and ambiguity. The regression analysis of the Slovene participant data did not confirm a quadratic relationship between familiarity and emotional valence, and the regression analysis of the German data did not show any significant effect of transparency and ambiguity (i.e., literal plausibility). These results suggest that second language processing of idioms compared to first language processing relies more strongly on transparency and literal plausibility and less strongly on emotional aspects of complex language expressions.

Regression models with emotional arousal as dependent variable. The ordinary least squares regression model S2 for the estimation of emotional arousal of the Slovene participants, including five significant predictors and one marginally significant variable (i.e., log (Length.L)), can account for $40 \%$ of the variance $\left(\mathrm{R}^{2}=0.40 ; \mathrm{r}=0.64 ; \mathrm{F}(6,612)=69.14 ; \mathrm{p}<0.001\right)$, with ambiguity excluded 39\% $\left(\mathrm{R}^{2}=0.39 ; \mathrm{r}=0.63 ; \mathrm{F}(5,613)=79.19 ; \mathrm{p}<0.001\right)$; transparency, concreteness, and confidence were not significant $(\mathrm{p}>0.05)$ :

(S2) Estimated emotional arousal $=1.81-0.12 *$ emotional valence + $0.17 *$ emotional valence ${ }^{2}+0.22 *$ familiarity $+0.16^{*}$ figurativeness + $0.11 * \log ($ Length.L $)-0.30 *$ ambiguity.

In contrast to our regression above, the mixed effects regression model S3 also accounted for two random effects (participants and idioms) and thus resulted in seven significant main effects $\left(\mathrm{AIC}=157514 ; \chi^{2}(7)=2030.2\right.$; $\mathrm{p}<0.001-$ compared to the null model with random effects only, AIC $=159530$ ); concreteness and idiom length were not significant $(\mathrm{p}>0.05)$ :

(S3) Estimated emotional arousal $=2.59-0.05 *$ emotional valence + $0.08 *$ emotional valence ${ }^{2}+0.08 *$ familiarity $+0.05 *$ transparency + $0.07 *$ figurativeness $+0.05 *$ confidence $-0.06 *$ ambiguity $+(1 \mid$ Participants $)$ $+(1 \mid$ Idioms $)$.

According to model S3, higher levels of familiarity, transparency, figurativeness, confidence and valence squared increased the levels of emotional arousal in the data of the Slovene participants. Negative valence was more stimulating than positive valence. Idiom ambiguity, rated by the Slovene participants, decreased emotional arousal levels. 
According to both models (S2 and S3), the Slovene second language learners attributed higher levels of emotional arousal to more negatively rated, higher valenced, more familiar and more figurative German idioms than to positively rated, lower valenced, less familiar and less figurative idioms. The predictor idiom length was marginally significant in model S2, that is, idiom length had a small positive effect on arousal levels, but after also accounting for random effects in model S3, semantic transparency and confidence (i.e., referring to idiomatic knowledge) turned significant instead. In both models, concreteness was not significant. The significant impact of ambiguity on arousal levels was dealt with in the former section on partial correlations.

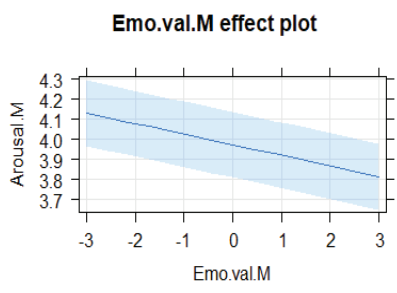

Length.L effect plot

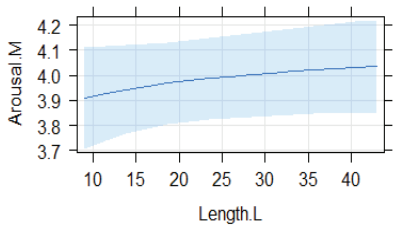

Figurative.M effect plot

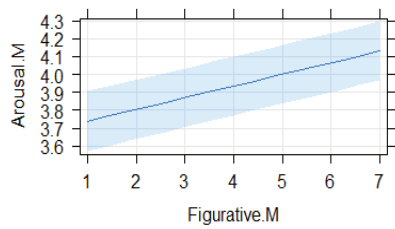

Emo.val.Msq effect plot

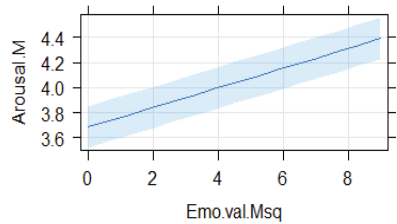

Familiarity.M effect plot

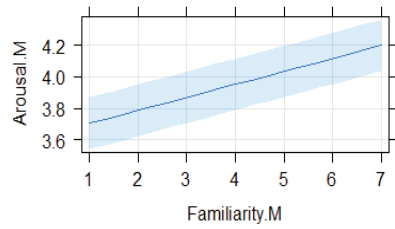

Ambiguity effect plot

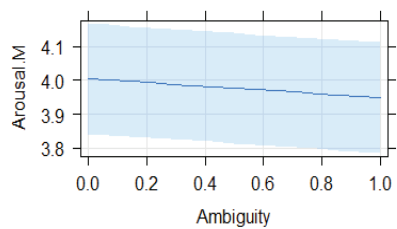

Concrete.M effect plot

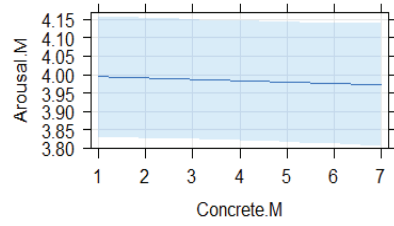

Sem.transp.M effect plot

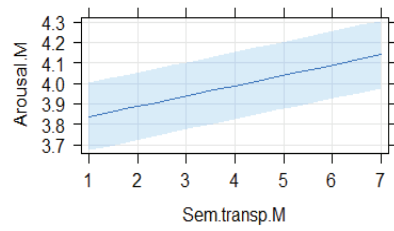

Confidence.M effect plot

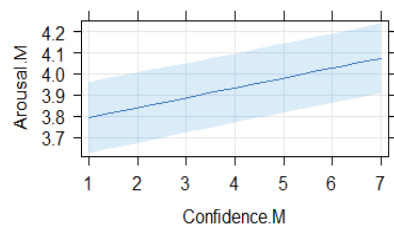

Figure 4. Mixed effects regression model S3.

The regression models of the Slovene evaluation data (S2 and S3) are in line with our above stated expectations and resemble the model of the German evaluation data (G2) in several aspects. The regression line was as follows (cf. Citron et al. (2015, p. 11)):

(G2) Estimated emotional arousal $=0.15 *$ familiarity $+0.13 *$ concreteness + $0.29 *$ figurativeness $+0.15 *$ semantic transparency $-0.13 *$ emotional valence $+0.48 *$ emotional valence. ${ }^{2}$ 
In both participant groups, higher levels of arousal were attributed to more familiar, more figurative, emotionally less neutral and more negative German idioms. However, in the data of the German participants, concreteness was a significant predictor. Another difference worth mentioning was that familiarity in the Slovene models (S2 and S3) showed a stronger effect on higher levels of emotional arousal than figurativeness and squared emotional valence, whereas in the German participant model G2, we could observe the opposite. Furthermore, concreteness seemed to be conceptually less clear to the Slovene participants than ambiguity (i.e., literal plausibility), thus only the latter showed a significant effect on arousal levels.

\section{Conclusion}

The aims of this study were to provide second language norms for psycholinguistic and affective properties of German idioms in second language processing, to explore the relationships between them, and to compare the ratings of Slovene second language learners (from our study) with those of German native speakers (studied in Citron et al., 2015).

In our summary, we first turn to the relationships concerning emotional variables. In both studies the participants associated more valenced idiomatic meanings with higher levels of arousal, with negative idioms leading to a higher level of arousal than positive idioms. These results may reflect the tendency that non-literal expressions are preferred over literal ones when speakers make negative statements (cf. Cacciari, 1998; Drew \& Holt, 1988). However, the ratings of the Slovene participants indicated a slight positivity bias compared to those of the German participants. This result may lend some support for the view that a positivity bias is to be expected in second language processing (cf. Schumann, 1998). Furthermore, the non-linear (U-shaped) relationship between arousal and valence was less pronounced in the data of the Slovene participants than in the data of the German participants. These details may support the view of attenuated emotionality (or emotional detachment) of second language processing (cf. Harris, 2004).

The preference for non-literal expressions in emotionally less desirable situations was also indirectly supported by the tendency of both participant groups to associate more figurative idioms with higher levels of arousal, and by the tendency of the Slovene participants to associate them with higher levels of valence. According to Citron et al. (2015) these results may reflect a general feature of language since also obtained with single words (e.g., Citron et al., 2014; Võ et al., 2009). 
The positive correlation of semantic transparency and arousal, observed in both participant groups, seems to support the assumption that it is easier to attribute high arousal values to idioms in which the literal meaning of the constituent words clearly contributes to the idiomatic interpretation.

In both participant groups, emotional valence and arousal had a positive linear correlation with familiarity, which supports the assumption that it is easier to attribute higher levels of valence and arousal to familiar idioms. But in contrast to the German participant group, the data of the Slovene participants did not confirm a negative quadratic relationship between valence and familiarity. The authors of the study Citron et al. (2015, p. 11) argue that the negative quadratic relationship in the German participant data could be connected with higher token frequency of positive idioms in speech.

In the data of the German participant group, concreteness was positively correlated with emotional arousal, supporting the assumption that concrete concepts with a direct reference to sensory modalities may be seen as more linked to physiological states (Citron et al., 2015, p. 11). This assumption was not confirmed in the data of the Slovene participants. The correlation analysis in our study indicates that concreteness, being substantially moderated by transparency and ambiguity, may be a less reliable scale in second language analysis. Many idiom meanings appear to be stored and comprehended with the support of mental images (e.g., the idiom constituent Kater in the opaque German idiom einen Kater haben, "to have a hangover," but literally "to have a male cat"). Thus, idiomatic meanings, though abstract in meaning, can be associated with high levels of imageability. A positive correlation between emotional arousal and imageability has been already observed with single words (Citron et al., 2015, p. 11; Ljubešić, Fišer, \& Peti-Stantić, 2018).

Ambiguity was determined by the experimenters of Citron et al. (2015), but also by the Slovene participants. Ambiguity determined by the experimenters was included in our comparisons of the German and Slovene participants. The data of both participant groups showed negative correlations between ambiguity and both affective variables, that is, idioms without a plausible literal meaning were associated with higher levels of valence and arousal. Citron et al. (2015, p. 13) argue that the potential literal meaning of ambiguous idioms interferes with its idiomatic meaning and reduces emotional rating values, but makes it easier to produce mental images which can be more directly associated with sensory modalities.

In contrast to the German participant data, the Slovene data did not show any significant partial correlations between idiom length and valence.

We now turn to the relationships among the psycholinguistic variables (familiarity, transparency, figurativeness, concreteness, idiom length, confidence, and idiomatic knowledge). In the ratings of the German participants, familiarity (i.e., subjective frequency) was positively correlated with knowledge of the 
idiomatic meaning (Citron et al., 2015, p. 12), confirming previous findings exploring idiomatic knowledge or confidence (Bonin et al., 2013; Libben \& Titone, 2008; Tabossi et al., 2011; Titone \& Connine, 1994). Since knowledge had not been included in the analysis of the Slovene participant data, we obtained results from confidence, which was also designed to capture knowledge. In contrast to the data of the German participants, the results of the Slovene second language learners confirm a strong positive relationship of confidence with familiarity and a moderate positive correlation with transparency and figurativeness. The positive partial correlation between confidence and figurativeness resulted from the moderating effect of transparency, that is, confidence was highest if transparency reached high levels and figurativeness low levels. Citron et al. (2015) argue that confidence may not necessarily be a reliable measure of the actual knowledge of an idiomatic meaning, which is better captured by familiarity and asking participants to write the meaning down.

In the data of the Slovene second language learners, the perceived level of figurativeness of an idiom was negatively correlated with semantic transparency and concreteness and positively with familiarity. The more idiomatic a meaning was, the less semantically transparent and concrete it was rated. However, the more idiomatic a meaning was, the more familiar it was rated. The positive partial correlation seems to be a moderating effect of transparency: the familiarity ratings reached their lowest levels if idiom transparency was rated low and figurativeness high. The correlations of figurativeness with transparency and concreteness replicate the results of the German native speakers in Citron et al. (2015). The meanings of most idiomatic strings were unrelated to the literal meaning of the constituent words, and predominantly conveyed abstract contents.

According to Citron et al. (2015), the German participants perceived shorter idioms as more familiar and longer idioms as providing more semantic information than shorter idioms, facilitating their figurativeness and semantic transparency. Similar results were found in the partial correlation results of the Slovene participant group: idiom length (measured as number of words or letters) was negatively correlated with familiarity and positively with figurativeness and concreteness.

In contrast to the data of the German participants, where semantic transparency was not correlated with familiarity (in line with Tabossi et al., 2011; but see Abel, 2003) or with idiom knowledge (unlike Tabossi et al., 2011), the data of the Slovene participants showed a strong positive correlation between familiarity and semantic transparency. Citron et al. (2015) argue that the results of the German participants seem to reflect the fact that storage and retrieval of familiar idioms is of no need to detect a clear relationship between the component word meanings and the global figurative interpretation of the string (Bonin et al., 2013; Libben \& Titone, 2008; Titone \& Connine, 1994). In contrast, stor- 
age and retrieval in a (first or second) language acquisition setting seems to rely to a greater extent on the literal meaning of figurative expressions (cf. Abel, 2003) and their transparency, that is, to establish a post-hoc link between an idiomatic meaning and its individual components (cf. Cacciari, 2014). According to Nippold and Taylor (2002), who compared transparency judgements of children and adolescents in their native language, found that for the children the easiest idioms were more familiar and transparent than the most difficult idiomatic expressions. Our conclusion is that such a correlation may be also typical in second language judgements.

Furthermore and in contrast with the L1 German, the data of the Slovene participants showed a moderate positive correlation between transparency and concreteness. The more concrete an idiom was rated, the more it was transparent. In comparison to the German native speakers, the second language learners in our study showed a moderate tendency to refer to the meaning of individual idiom components and the accessibility of their meaning on a sensory level.

Ambiguity (i.e., potential literal plausibility of idioms) had mainly an inhibitory effect on other variables in the data of both participant groups: ambiguous idioms were less emotionally salient (i.e., rated as less valenced and arousing) and more linked to concrete, sensory-based information than were unambiguous idioms. They were less correctly defined by the German participants (not analyzed in the data of the Slovene participants), and rated less figurative by the Slovene participants than unambiguous idioms. Citron et al. (2015) argue that the literal meaning might represent a source of possible interference in ambiguous idioms, which leads to the preference of sensory-based information and lower emotional salience. In the data of the Slovene participants, ambiguity reached its highest levels if concreteness values were high and figurativeness low.

Hopefully, our descriptive and comparative study provides some insight into the relationships between figurative language and affect in second language processing and will prove to be useful for further research in this field. Much like other normative studies, it shows a lower degree of inter-rater reliability (tested with Krippendorff's alpha), but it shows high reliability - that is, internal consistency (tested with Cronbach's alpha). To our knowledge, several psycholinguistic and affective variables (such as emotional arousal and valence, concreteness, figurativeness) were not tested in previous normative studies on German idioms in second language processing, but can be taken into account in upcoming experimental settings and other applications. 


\section{References}

Abel, B. (2003). English idioms in the first language and second language lexicon: A dual representation approach. Second Language Research, 19, 329-358.

Barrett, L. F., \& Russell, J. A. (1998). Independence and bipolarity in the structure of current affect. Journal of Personality and Social Psychology, 74, 967-984.

Beck, S. D., \& Weber, A. (2016). Bilingual and monolingual idiom processing is cut from the same cloth: The role of the L1 in literal and figurative meaning Activation. Frontiers in Psychology, 7, 1-16. doi: 10.3389/fpsyg.2016.01350

Beeman, M. (1998). Coarse semantic coding and discourse comprehension. In M. Beeman \& C. Chiarello (Eds.), Right hemisphere language comprehension: Perspectives from cognitive neuroscience (pp. 255-284). Mahwah, NJ: Erlbaum.

Bobrow, S. A., \& Bell, S. M. (1973). On catching on to idiomatic expressions. Memory \& Cognition, 1, 343-346. doi: 10.3758/BF03198118

Bohrn, I., Altmann, U., Lubrich, O., Menninghaus, W., \& Jacobs, A. M. (2012). Old proverbs in new skins-An fMRI study on defamiliarization. Frontiers in Psychology, 3, 204. doi: 10.3389/fpsyg.2012.00204

Bond, M. H., \& Lai, T. (1986). Embarrassment and code-switching into a second language. Journal of Social Psychology, 126, 179-186.

Bonin, P., Méot, A., \& Bugaiska, A. (2013). Norms and comprehension times for 305 French idiomatic expressions. Behavior Research Methods, 45, 1259-1271. doi: 10.3758/s13428-0130331-4

Bradley, M. M., \& Lang, P. J. (1999). Affective norms for English words (ANEW): Stimuli, instruction manual and affective ratings. Gainesville: NIMH Center for Research in Psychophysiology, University of Florida.

Cacciari, C. (1998). Why do we speak metaphorically? Reflections on the functions of metaphor in discourse and reasoning. In A. N. Katz, C. Cacciari, R. W. Gibbs, \& M. Turner (Eds.), Figurative language and thought (pp. 119-158). Oxford: Oxford University Press.

Cacciari, C. (2014). Processing multiword idiomatic strings: Many words in one? Mental Lexicon, 9, 267-293.

Cacciari, C., \& Glucksberg, S. (1994). Understanding figurative language. In M. A. Gernsbacher (Ed.), Handbook of psycholinguistics (pp. 447-477). San Diego: Academic Press.

Cacciari, C., \& Tabossi, P. (1988). The comprehension of idioms. Journal of Memory and Language, 27, 668-683.

Citron, F. M. M., \& Goldberg, A. E. (2014). Metaphorical sentences are more emotionally engaging than their literal counterparts. Journal of Cognitive Neuroscience, 26, 2585-2595. doi: 10.1162/jocn_a_00654

Citron, F. M. M., Weekes, B. S., \& Ferstl, E. C. (2014). How are affective word ratings related to lexico-semantic properties? Evidence from the Sussex Affective Word List (SAWL). Applied Psycholinguistics, 35, 313-331. doi: 10.1017/S0142716412000409

Citron, F. M. M., Cacciari, C., Kucharski, M., Beck, L., Conrad, M., \& Jacobs, A. M. (2015). When emotions are expressed figuratively: Psycholinguistic and affective norms of 619 idioms for German (PANIG). Behaviour Research Methods, March 2015, 1-22. doi: 10.3758 /s13428-015-0581-4

Cieślicka, A. B. (2006). Literal salience in on-line processing of idiomatic expressions by L2 speakers. Second Language Reserach, 22, 115-144. doi: 10.1191/0267658306sr263oa 
Cieślicka, A. B. (2015). Idiom acquisition and processing by second/foreign language learners. In R. R. Heredia \& A. B. Cieślicka (Eds.), Bilingual Figurative Language Processing (pp. 208-244). Cambridge: Cambridge University Press. doi: 10.1017/CBO9781139342100.012

Conklin, K., \& Schmitt, N. (2008). Formulaic sequences: Are they processed more quickly than nonformulaic language by native and non-native speakers? Applied Linguistics, 29, 72-89.

Conrad, M., Recio, G., \& Jacobs, A. M. (2011). The time course of emotion effects in first and second language processing: A cross cultural ERP study with German-Spanish bilinguals. Frontiers in Psychology, 2, 351. doi: 10.3389/fpsyg.2011.00351

Cronk, B. C., Lima, S. D., \& Schweigert, W. A. (1993). Idioms in sentences: Effects of frequency, literalness, and familiarity. Journal of Psycholinguistic Research, 22, 59-82.

Drew, P., \& Holt, E. (1988). Complainable matters: The use of idiomatic expressions in making complaints. Social Problems, 35, 398-417.

Drew, P., \& Holt, E. (1998). Figures of speech: Figurative expressions and the management of topic transition in conversation. Language in Society, 27, 495-522.

Efron, B., \& Tibshirani, R. (1993). An introduction to the bootstrap. Boca Raton: Chapman \& Hall/CRC.

Ephras (2006). Ephras. Ein mehrsprachiges phraseologisches Lernmaterial auf CD-ROM. Sokrates Lingua-Projekt 2004-2006, geleitet von Vida Jesenšek. Maribor: Universität Maribor.

Fainsilber, L., \& Ortony, A. (1987). Metaphorical uses of language in the expression of emotions. Metaphor and Symbolic Activity, 2, 239-250.

Fox, J. (2017). Using the $R$ commander: A point-and-click interface or R. Boca Raton FL: Chapman \& Hall/CRC Press.

Gamer, M., Lemon, J., \& Singh, I. F. P. (2012). irr: Various coefficients of interrater reliability and agreement. $R$ package version 0.84 Accessed: 5.04.2018. Retrieved from: https:// CRAN.R-project.org/package $=$ irr

Gibbs, R. W., Nayak, N. P., \& Cutting, C. (1989). How to kick the bucket and not decompose: Analyzability and idiom processing. Journal of Memory and Language, 28, 576-593. doi: 10.1016/0749-596X(89)90014-4

Giora, R. (2003). On our mind: Salience, context, and figurative language. Oxford: Oxford University Press.

Harris, C. (2004). Bilingual speakers in the lab: Psychophysiological measures of emotional reactivity. Journal of Multilingual and Multicultural Development, 25, 223-247.

Jacobs, A. M. (2011). Neurokognitive Poetik: Elemente eines Modells des literarischen Lesens. In R. Schrott \& A. M. Jacobs (Eds.), Gehirn und Gedicht: Wie wir unsere Wirklichkeiten konstruieren (pp. 492-520). Munich: Hanser.

Jacobs, A. M., Võ, M. L.-H., Briesemeister, B. B., Conrad, M., Hofmann, M. J., Kuchinke, L., \& Braun, M. (2015). Ten years of BAWLing into affective and aesthetic processes in reading: What are the echoes? Manuscript under review at Frontiers in Psychology.

Jesenšek, V. (ed.). (2014). Frazeologija nemškega jezika z vidikov kontrastivnega in uporabnega jezikoslovja [Phraseology of the German Language from the Perspective of Contrastive and Applied Linguistics]. Maribor: Filozofska fakulteta Univerze v Mariboru.

Kline, P. (1999). The handbook of psychological testing (2nd ed.). London: Routledge.

Libben M. R., \& Titone D. A. (2008). The multidetermined nature of idiom processing. Memory \& Cognition, 36, 1103-1121. doi: 10.3758/MC.36.6.1103

Liontas, J. I. (2002). Context and idiom understanding in second languages. In S. H. FosterCohen, T. Ruthenberg, \& M.-L. Poschen (Eds.), EUROSLA Yearbook: Annual conference of the European Second Language Association (pp. 155-185). Amsterdam-Philadelphia: John Benjamins. 
Ljubešić, N., Fišer, D., \& Peti-Stantić, A. (2018). Predicting concreteness and imageability of words within and across languages via word embeddings. Proceedings of the $3 r d$ Workshop on Representation Learning for NLP. Melbourne, Australia, July 20, 217-222.

Matlock, T., \& Heredia, R. R. (2002). Understanding phrasal verbs in monolinguals and bilinguals. Bilingual Sentence Processing, 134, 251-274. doi: 10.1016/S0166-4115(02)80014-0

Montefinese, M., Ambrosini, E., Fairfield, B., \& Mammarella, N. (2014). The adaptation of the Affective Norms for English Words (ANEW) for Italian. Behavior Research Methods, 46, 887-903. doi: 10.3758/s13428-013-0405-3

Nippold, M. A., \& Taylor, C. L. (2002). Judgments of Idiom Familiarity and Transparency. A Comparison of Children and Adolescents. Journal of Speech Language and Hearing Research 45(2): 384-391. doi: 10.1044/1092-4388(2002/030)

Nordmann, E., \& Jambazova, A. A. (2017). Normative data for idiomatic expressions. Behavior Research Methods, 49, 198-215. doi: 10.3758/s13428-016-0705-5

Nordmann, E., Cleland, A. A., \& Bull, R. (2014). Familiarity breeds dissent: Reliability analyses for British-English idioms on measures of familiarity, meaning, literality, and decomposability. Acta Psychologica, 1 49, 87-95. doi: 10.1016/j.actpsy.2014.03.009

Paivio, A. (2007). Mind and its evolution: A dual coding theoretical approach. Mahwah: Erlbaum.

Pena, E. A., \& Slate, E. H. (2014). gvlma: Global Validation of Linear Models Assumptions. R package version 1.0.0. Accessed: 5.04.2018. Retrieved from: https://CRAN.R-project.org/ package $=$ gvlma

Petrič, T. (2014). Modeli kognitivne obdelave kompleksnih slovarskih enot na primeru nemških in slovenskih frazemov [Cognitive processing models of complex lexicon items exemplified on German and Slovene phrasemes]. In V. Jesenšek (Ed.), Frazeologija nemškega jezika $z$ vidikov kontrastivnega in uporabnega jezikoslovja [Phraseology of the German Language from the Perspective of Contrastive and Applied Linguistics] (pp. 180-281). Maribor: Filozofska fakulteta.

Pollio, H. R., Barlow, J. M., Fine, H. J., \& Pollio, M. R. (1977). Psychology and the poetics of growth: Figurative language in psychology, psychotherapy, and education. Hillsdale: Erlbaum.

Prabhakaran, S. (2017). 10 assumptions of linear regression - Full list with examples and code. Accessed: 5.04.2018. Retrieved from: http://r-statistics.co/Assumptions-of-LinearRegression.html

Revelle, W. (2018). psych: Procedures for personality and psychological research. Northwestern University, Evanston, IL, USA. Accessed: 5.04.2018. Retrieved from: https://CRAN.Rproject.org/package $=$ psychVersion $=1.8 .4$

Ruginski, I. (2016). Checking the assumptions of linear regression. Accessed: 11.10.2018. Retrieved from: http://psych.utah.edu/people/graduate-students/ruginski-ian.php

Russell, J. A. (1980). A circumplex model of affect. Journal of Personality and Social Psychology, 39, 1161-1178. doi: 10.1037/h0077714

Sabsevitz, D. S., Medler, D. A., Seidenberg, M. S., \& Binder, J. R. (2005). Modulation of the semantic system by word imageability. NeuroImage, 27, 188-200. doi: 10.1016/j.neuroimage.2005.04.012

Schumann, J. H. (1998). The neurobiology of affect in language. Oxford: Blackwell.

Seongho, K. (2015). ppcor: Partial and semi-partial (part) correlation. $R$ package version 1.1. Accessed: 5.04.2018. Retrieved from: https://CRAN.R-project.org/package=ppcor

Siyanova-Chanturia, A., Conklin, K., \& Schmitt, N. (2011). Adding more fuel to the fire: An eye-tracking study of idiom processing by native and non-native speakers. Second Language Research, 27, 251-272. 
Sprenger, S. A., Levelt, W. J. M., \& Kempen, G. (2006). Lexical access during the production of idiomatic phrases. Journal of Memory and Language, 54, 161-184.

Swinney, D. A., \& Cutler, A. (1979). The access and processing of idiomatic expressions. Journal of Verbal Learning and Verbal Behavior, 18, 523-534. doi: 10.1016/S0022-5371(79)90284-6

Tabossi, P., Arduino, L., \& Fanari, R. (2011). Descriptive norms for 245 Italian idiomatic expressions. Behavior Research Methods, 43, 110-123. doi: 10.3758/s13428-010-0018-z

Titone, D. A., \& Connine, C. M. (1994). Descriptive norms for 171 idiomatic expressions: Familiarity, compositionality, predictability and literality. Metaphor and Symbolic Activity, 9, 247-270.

Titone, D. A., Columbus, G., Whitford, V., Mercier, J., \& Libben, M. R. (2015). Contrasting bilingual and monolingual idiom processing. In R. R. Heredia \& A. B. Cieślicka (Eds.), Bilingual Figurative Language Processing (pp. 171-207). New York: Cambridge University Press.

Turner, N., \& Katz, A. (1997). The availability of conventional and of literal meaning during the comprehension of proverbs. Pragmatics and Cognition, 5, 199-233.

Udem, P. (2001). Redensarten-Index: Wörterbuch für Redensarten, Redewendungen, idiomatische Ausdrücke, feste Wortverbindungen. Accessed: 1.12.2013. Retrieved from: www. redensarten-index.de

Võ, M. L.-H., Conrad, M., Kuchinke, K., Urton, K., Hofmann, M. J., \& Jacobs, A. M. (2009). The Berlin affective word list reloaded. Behavior Research Methods, 41, 534-538.

Teodor Petrič

\section{Bewertungen affektiver und nicht-affektiver Aspekte von Idiomen im Deutschen als Zweitsprache}

\section{Zusammenfassung}

Dieser Beitrag präsentiert die Ergebnisse einer zweitsprachlichen Untersuchung psycholinguistischer und affektiver Eigenschaften von 619 deutschen idiomatischen Wortverbindungen, die zuvor von Citron et al. (2015) gesammelt und von deutschen Muttersprachlern bewertet wurden. In unserer Studie wurden dieselben Redewendungen von slowenischen Lernern des Deutschen als Fremdsprache bewertet. Unsere Probanden stuften jede Redewendung in Bezug auf emotionale Wertigkeit, emotionale Erregung, Bekanntheitsgrad, Konkretheit, Ambiguität (wörtliche Bedeutung), semantische Transparenz und Bildhaftigkeit ein.Unser Beitrag hatte die folgenden Ziele: (1) deskriptive Normwerte für psycholinguistische und affektive Eigenschaften von idiomatischen Wortverbindungen im Deutschen als Zweitsprache zu erschließen, (2) die in der Zweitsprache charakteristischen Beziehungen zwischen affektiven und nicht-affektiven Eigenschaften von Idiomen zu untersuchen und (3) die Bewertungen der in Citron et al. (2015) untersuchten deutschen Muttersprachler mit denen slowenischer DaF-Lerner zu vergleichen. [This paragraphismissing in the Englisch abstract: $\mathrm{Zu}$ diesem Zweck erhielten unsere slowenischen Probanden dieselbe Idiom-Liste und dieselben Aufgaben wie die von Citron et al. (2015) untersuchten deutschen Muttersprachler, und zwar jede der (ambigen oder nicht-ambigen) idiomatischen Wortverbindungen hinsichtlich emotionaler Valenz, emotionaler Intensität, Gebräuchlichkeit, Konkretheit, semantischer Durchsichtigkeit, Metaphorizität sowie hinsichtlich ihres idiomatischen Wissens (Zuversicht) zu bewerten.] Die Ergebnisse der slowenischen Probanden zeigen einerseits große Übereinstimmungen mit denen der deutschen Muttersprachler, andererseits aber auch eine leichte Neigung zu positiven Einstellung 
und eine etwas oberflächlichere emotionale Verarbeitung der deutschen Idiome. Die Untersuchungsergebnisse könnten in zukünftigen Studien (in den Bereichen Sprachmethodik, Translationswissenschaft, computerunterstützte Sprachgenerierung), in denen die Rolle von affektiven Eigenschaften idiomatischer Ausdrücke untersucht wird, von Nutzen sein.

Schlüsselwörter: idiomatische Wortverbindungen, affektive Eigenschaften, psycholinguistische Eigenschaften, Deutsch, Slowenisch 